\title{
ORIGINAL RESEARCH • RECHERCHE ORIGINAL
}

\section{AdVAnCES}

\section{Can urine cultures and reagent test strips be used to diagnose urinary tract infection in elderly emergency department patients without focal urinary symptoms?}

\author{
James Ducharme, MD; Shane Neilson, MD; Jeffery L. Ginn, MD
}

\begin{abstract}
Objective: To compare the results of urine cultures and reagent strip testing in 2 groups of elderly emergency department (ED) patients: an asymptomatic group unlikely to have urinary tract infection (UTI), and a group who had vague symptoms and were considered at risk for UTI.

Methods: We performed a prospective observational convenience study with 2 groups of 100 patients aged 65 or older. The asymptomatic group consisted of afebrile patients presenting to the ED with non-infectious complaints, while the symptomatic group included patients presenting with acute confusion, weakness or fever but no apparent urinary symptoms. We defined a positive urine culture as a single organism count greater than $100000 \mathrm{CFU} / \mathrm{mL}$ in mid-stream specimens, or greater than $1000 \mathrm{CFU} / \mathrm{mL}$ in catheter specimens. We considered reagent strips positive if they demonstrated any reaction to the leukocyte-esterase assay, the nitrite assay or both.

Results: Of the 33 positive cultures, 10 had negative reagent strips. Thirteen of the 14 positive nitrite tests were culture positive for a specificity of $92.8 \%$ and a sensitivity of $36.1 \%$. Positive cultures did not infer a diagnosis of UTI. Of the 67 positive reagent strips, $41(61.2 \%)$ were associated with negative cultures. Likelihood ratios (LRs) in both groups affirmed the inability of the reagent strips to help significantly in decision making, with positive and negative LR in the indeterminate range (control group: 2.8 and 0.31 , symptomatic group: 2.7 and 0.46 , respectively).

Conclusion: In the elderly, reagent testing is an unreliable method of identifying patients with positive blood cultures. Moreover, positive urine culture rates are only slightly higher in patients with vague symptoms attributable to UTI than they are in (asymptomatic) patients treated for non-urologic problems, which suggests that many positive cultures in elderly patients with nonfocal systemic symptoms are false-positive tests reflecting asymptomatic bacteriuria and not UTIs. Blood cultures, regarded by many as the criterion standard for UTI, do not have sufficient specificity to confirm the diagnosis of UTI in elderly patients with non-specific symptoms.
\end{abstract}

Key words: urinary tract infection, elderly, diagnosis

RÉSUMÉ

Objectifs : Comparer les résultats de cultures d'urine et de tests par bandelettes réactives chez deux groupes de patients âgés à l'urgence : un groupe de sujets asymptomatiques peu susceptibles 
d'avoir une infection urinaire et un groupe de sujets présentant de vagues symptômes et jugés à risque d'infection urinaire.

Méthodes : Nous avons procédé à une étude prospective de commodité par observation portant sur 2 groupes de 100 patients âgés de 65 ans ou plus. Le groupe de sujets asymptomatiques était constitué de patients afébriles qui se sont présentés à l'urgence en se plaignant de problèmes non infectieux tandis que le groupe des sujets symptomatiques incluait des patients très confus, faibles ou fiévreux, mais sans symptômes urinaires apparents à leur arrivée. Nous avons considéré qu'une culture d'urine était positive lorsqu'elle contenait plus $100000 \mathrm{CFU} / \mathrm{mL}$ d'un seul organisme dans des spécimens prélevés en milieu de jet ou plus de 1000 CFU/mL dans des spécimens prélevés par cathéter. Nous avons considéré que les bandelettes réactives donnaient un résultat positif si elles montraient une réaction au dosage leucocyte-estérase, au dosage des nitrites, ou aux deux.

Résultats : Des 33 cultures positives, 10 étaient négatives aux bandelettes réactives; 13 des 14 dosages des nitrites positifs ont produit une culture positive, ce qui donne une spécificité de $92,8 \%$ et une sensibilité de $36,1 \%$. Les cultures positives n'indiquaient pas nécessairement un diagnostic d'infection urinaire. Des 67 bandelettes réactives qui ont produit un résultat positif, on a établi un lien entre avec des cultures négatives dans $41(61,2 \%)$ des cas. Les tests du rapport de vraisemblance (RV) effectués dans les deux groupes ont confirmé l'incapacité des bandelettes réactives d'aider vraiment à prendre une décision et les RV positifs et négatifs se sont établis dans la plage indéterminée (groupe témoin : 2,8 et 0,31 ; groupe symptomatique : 2,7 et 0,46 , respectivement).

Conclusions : Chez les personnes âgées, le test aux bandelettes réactives n'est pas une méthode fiable pour repérer les patients dont les cultures sanguines donnent des résultats positifs. De plus, les taux de cultures d'urine positives sont à peine un peu plus élevés chez les patients qui présentent de vagues symptômes attribuables à une infection urinaire que chez les patients (asymptomatiques) traités pour des problèmes non urologiques, ce qui indique que beaucoup de cultures positives prélevées chez des patients âgés présentant des symptômes systémiques non focalisés sont faussement positives et révèlent une bactériurie asymptomatique et non une infection urinaire. Par ailleurs, les cultures sanguines considérées par beaucoup comme l'étalon critère de l'infection urinaire ne sont pas suffisamment spécifiques pour confirmer le diagnostic d'infection urinaire chez les patients âgés qui présentent des symptômes non spécifiques.

\section{Introduction}

Although asymptomatic bacteriuria in the elderly is a well recognized phenomenon, ${ }^{1}$ the transition from this to a urinary tract infection (UTI) may be difficult to define. Emergency physicians (EPs) justifiably suspect UTIs in elderly patients who have vague, systemic complaints, since nonspecific presentations of UTI are relatively frequent. $.^{2-4} \mathrm{Be}-$ cause UTI may cause substantial morbidity and mortality in the elderly, physicians frequently initiate antibiotics based on positive urinary reagent strip tests until culture results are available. With such an approach, misdiagnosis of a UTI has been estimated to range from $20 \%-40 \% .^{5}$ In addition, this management plan may be incorrectly reinforced by the subsequent return of positive urine cultures, which are in fact related to pre-existing asymptomatic bacteriuria. If the rates of positive urinary tests (reagent strips and cultures) in a population of elderly patients with vague symptoms are similar to the rates of positive tests in a population with asymptomatic bacteriuria, it is likely that EPs are treating "background" noise and not true infections.
A MEDLINE search, using the MeSH terms elderly, geriatric, urinary tract infection, therapy and diagnosis, failed to identify any ED-based studies addressing the diagnosis of UTI using reagent strips in the elderly. In this study, we sought to compare the results of urine cultures and reagent strips in 2 groups of elderly emergency department (ED) patients: an asymptomatic group unlikely to have UTI, and a group who had vague symptoms and were considered at risk for UTI.

\section{Methods}

\section{Setting and patients}

This observational, cohort study was conducted in a university teaching hospital ED with an annual census of 60000 . We recruited 2 cohorts in a prospective convenience fashion, each included 100 patients aged 65 years or older. The first (asymptomatic) group consisted of afebrile patients who presented to the ED with non-infectious, non-systemic complaints such as minor trauma, nonspecific chest pain, cast checks or follow-up for other test 
results. The second (symptomatic) group consisted of patients who presented with acute confusion, weakness or fever without focal symptoms. In this group, UTI was considered a possible etiology for patients' non-specific presentation. We excluded patients who required hospital admission before screening, those with urinary symptoms (frequency, burning, dysuria, or costovertebral angle pain or tenderness), those with known anatomic urological abnormalities and those residing in long-term care facilities. This study was approved by the Research Review Committee of our hospital, and all patients provided written consent before participating.

\section{Study procedures}

We performed reagent strip testing and urine cultures for patients in both groups. At the time of specimen collection, the EPs were not aware of the asymptomatic group's strip testing results. Treating physicians were aware of the symptomatic group's reagent test results as urine testing is routine for this patient group. On day 3, research assistants reviewed all culture results and provided the on-site EP with the patient chart and culture results if a positive culture was identified. The on-site EP determined whether or not any additional follow-up or treatment was needed. For patients admitted to the hospital, culture results were forwarded to the appropriate ward.

\section{Definitions}

A positive urinary culture was defined a priori as a single organism count greater than $100000 \mathrm{CFU} / \mathrm{mL}$ in midstream specimens and greater than $1000 \mathrm{CFU} / \mathrm{mL}$ in specimens collected by catheterization. We considered reagent

Table 1. Study subjects and urine test results, by group.

\begin{tabular}{lcc} 
Variable & $\begin{array}{c}\text { Asymptomatic } \\
\text { group } \\
(n=100)\end{array}$ & $\begin{array}{c}\text { Symptomatic } \\
\text { group } \\
(n=100)\end{array}$ \\
\hline $\begin{array}{l}\text { Age in years, median } \\
\text { (IQR) }\end{array}$ & $78(71-83)$ & $79(74-85)$ \\
Gender, \% female & 53 & 55 \\
Catheter specimen, $n$ & 19 & 12 \\
$\quad n(\%)$ female & $13(68)$ & $9(75)$ \\
Positive culture, $n$ & $14^{*}$ & $19 \dagger$ \\
$n(\%)$ female & $9(64)$ & $15(79)$ \\
Positive nitrites, $n$ & 5 & 9 \\
$n(\%)$ female & $4(80)$ & $7(78)$ \\
Positive LE, $n$ & 28 & 38 \\
$n$ (\%) female & $20(71)$ & $30(79)$ \\
Positive nitrite or LE, $n$ & 29 & 38 \\
\hline * 4 were from catheters & & \\
†2 were from catheters & & \\
IQR $=$ interquartile range; LE $=$ leukocyte esterase & \\
\hline
\end{tabular}

strips positive if they demonstrated any reaction to the leukocyte-esterase assay, to the nitrite assay or to both. All assays were interpreted with an automated reagent strip analyzer (Clinitek 50, Bayer Corporation, Elkhart, IN) using the Multistix 8 SG reagent strip (Bayer HealthCare LLC, Elkhart, IN) used in the ED for this purpose. All testing was done by the emergency nurse responsible for the patient during the initial visit. No microscopic analysis was performed.

\section{Data analysis}

Results of reagent strip testing and urine cultures were collated and stratified by group. Descriptive data, including means, medians, interquartile ranges and 95\% confidence intervals (CIs) were calculated, as appropriate. We constructed standard $2 \times 2$ contingency tables to demonstrate the relations between reagent strip testing and urine culture results. We calculated sensitivity, specificity, predictive values and likelihood ratios (LRs) using standard formulae.

\section{Results}

There were 100 patients in each group. Table 1 shows that age and sex were similar between groups and that there was a slight preponderance of women in the study population.

\section{Asymptomatic group}

Patients in the asymptomatic group had the following presenting complaints: cardiac problem, including congestive heart failure, atrial fibrillation, acute coronary syndrome or chest pain $(n=29)$; dyspnea $(n=12)$; stroke or transient ischemic attack $(n=8)$; hip fracture $(n=7)$; abdominal pain $(n=7)$; back pain $(n=4)$; vertigo $(n=3)$; seizure $(n=3)$; vomiting $(n=3)$; upper gastrointestinal bleed $(n=2)$; anemia $(n=2)$; pleural effusion $(n=2)$; hypoglycemia $(n=2)$; and other miscellaneous complaints $(n=16)$. No patient in the asymptomatic group received antibiotics during the first ED visit or at discharge. Table 2 shows that 14 patients in this group had positive cultures and that, having a sensitivity of

\begin{tabular}{lccc}
$\begin{array}{l}\text { Table 2. Diagnostic parameters of reagent strips in } \\
\text { asymptomatic patients. }{ }^{*}+\end{array}$ & $\begin{array}{c}\text { Positive } \\
\text { culture }\end{array}$ & $\begin{array}{c}\text { Negative } \\
\text { culture }\end{array}$ & Total \\
Reagent strip & 9 & 20 & 29 \\
\hline Positive reagent strip & 5 & 66 & 71 \\
Negative reagent strip & 14 & 86 & 100 \\
Total &
\end{tabular}

*sensitivity $=64.3 \%$; specificity $=76.7 \%$; accuracy $=75 \%$

tpositive predictive value $=31 \%$; negative predictive value $=93 \%$ 
only $64.3 \%$ (95\% CI 35.6-86.0) and a specificity of $76.7 \%$ (95\% CI 66.2-84.9), reagent strips did not reliably predict culture results. In addition, 20 of the 29 patients who had positive reagent strip tests had negative cultures (positive predictive value $=31 \%$ ). Three days after the index visit, when results became available, 10 of 14 patients with positive cultures were treated with antibiotics despite the fact that they had no symptoms compatible with a UTI or with systemic illness.

\section{Symptomatic group}

Table 2 shows that 19 of 100 patients in this group had positive cultures and that reagent strips, with a sensitivity of only $73.7 \%$ (95\% CI 54.2-91.3) and a specificity of $70.4 \%$ (95\% CI 61.6-82.2), did not reliably predict culture results. In the symptomatic group, 24 of 38 patients with positive reagent strips had negative cultures (positive predictive value $=37 \%$ ). The physician response to reagent strip results was inconsistent in that physicians prescribed antibiotics for 21 of the 38 patients who had positive strip tests. Ten of the 19 subjects who had positive cultures received a diagnosis of UTI or urosepsis. Because reagent strip results were negative and because there were no localizing urinary symptoms, 5 patients with positive cultures were not diagnosed with UTIs.

\section{Test performance}

Table 2 and Table 3 show that sensitivity and specificity were similar, and relatively poor, in both groups. Positive likelihood ratios (LRs) for reagent test strips were 2.8 and 2.7 in the asymptomatic and symptomatic groups, respectively, while negative LRs were 0.3 and 0.46 . This suggests that these tests are both weak positive predictors and weak negative predictors.

Table 4 shows that Escherichia coli was the most commonly cultured pathogen but that a variety of enteric and other organisms were seen. A substantial number of patients had cultures that were interpreted as false positive. It was difficult to determine what proportion of positive cultures was owing to contamination or asymptomatic bacteriuria rather than to UTI.

\begin{tabular}{|c|c|c|c|}
\hline Reagent strip & $\begin{array}{l}\text { Positive } \\
\text { culture }\end{array}$ & $\begin{array}{c}\text { Negative } \\
\text { culture }\end{array}$ & Total \\
\hline Positive reagent strip & 14 & 24 & 38 \\
\hline Negative reagent strip & 5 & 57 & 62 \\
\hline Total & 19 & 81 & 100 \\
\hline \multicolumn{4}{|c|}{$\begin{array}{l}\text { *sensitivity }=73.7 \% ; \text { specificity }=70.4 \% ; \text { accuracy }=71 \% \\
\text { tpositive predictive value }=37 \% ; \text { negative predictive value }=92 \%\end{array}$} \\
\hline
\end{tabular}

\section{Discussion}

Based on these data, reagent strips are not effective for the accurate identification of acute UTIs in the elderly. Other studies provide conflicting results about their clinical value. In a meta-analysis, Deville and colleagues concluded that a reagent strip that was negative for both nitrites and leukocyte-esterase excluded the presence of infection (i.e., that the strip was highly sensitive). ${ }^{6}$ Conversely, reagent strips used in this fashion have many false-positives and are not specific enough to confirm infection, even in high pre-test probability situations. Eidelman and colleagues reported that reagent strips lacked sensitivity in the ED setting, even in high pre-test probability patients, and could therefore not rule out a UTI. ${ }^{7}$ Similarly, Lammers and others showed that when physicians relied on the reagent strip alone to evaluate patients with classic lower urinary tract symptoms, $47 \%$ of patients received antibiotics inappropriately, while $11 \%$ did not receive treatment when they should have. ${ }^{8}$

In this study, reagent strips were $64.3 \%$ and $73.7 \%$ sensitive for predicting positive urine cultures in asymptomatic and symptomatic patients, respectively. These values are lower than those quoted for the general adult population in a metaanalysis by DeVille and colleagues, who concluded that a negative reagent strip is sufficient to rule out

\begin{tabular}{|c|c|c|}
\hline $\begin{array}{l}\text { Pathogen } \\
\text { (n) }\end{array}$ & $\begin{array}{l}\text { Symptomatic } \\
\text { (n) }\end{array}$ & $\begin{array}{c}\text { Asymptomatic } \\
(n)\end{array}$ \\
\hline $\begin{array}{l}\text { Escherichia coli } \\
\text { (18) }\end{array}$ & 7 & 11 \\
\hline $\begin{array}{l}\text { Enterococcus } \\
\text { faecalis (3) }\end{array}$ & 3 & 0 \\
\hline $\begin{array}{l}\text { Staphylococcus } \\
\text { aureus (1) }\end{array}$ & 0 & 1 \\
\hline $\begin{array}{l}\text { Streptococcus } \\
\text { viridans (2) }\end{array}$ & 1 & 1 \\
\hline $\begin{array}{l}\text { Klebsiella } \\
\text { pneumoniae (5) }\end{array}$ & 4 & 1 \\
\hline $\begin{array}{l}\text { Citrobacter } \\
\text { freundii (1) }\end{array}$ & 1 & 0 \\
\hline Hafnia alvei (1) & 1 & 0 \\
\hline $\begin{array}{l}\text { Pseudomonas } \\
\text { aeruginosa (1) }\end{array}$ & 1 & 0 \\
\hline $\begin{array}{l}\text { Enterobacter } \\
\text { cloacae (1) }\end{array}$ & 1 & 0 \\
\hline Mixed flora* (17) & 10 & 7 \\
\hline $\begin{array}{l}\geq 2 \text { organisms with } \\
>10000 \mathrm{CFU}^{*}(4)\end{array}$ & 2 & 2 \\
\hline
\end{tabular}


urinary infection. Similar conclusions about poor sensitivity were reached for screening asymptomatic bacteriuria in pregnant women. ${ }^{9}$ The presence of asymptomatic bacteriuria is not infrequent in the elderly, and this may result in negative reagent testing but positive cultures. In addition, the presence of pyuria in association with asymptomatic bacteriuria has not been found to indicate antibiotic treatment. ${ }^{10}$ Given the prevalence of asymptomatic bacteriuria and the uncertainty of rapid diagnostic testing for UTI, the following question arises: In elderly patients with nonspecific symptoms, such as fever of unknown origin, confusion or weakness, how can EPs clarify whether a UTI is the etiology of these symptoms?

Barkham and colleagues showed that elderly patients with blood-culture positive urinary infections present with atypical symptoms more often than not. ${ }^{4}$ Surprisingly, confusion, cough and dyspnea were the 3 most common symptoms in patients who had urosepsis confirmed by positive blood and urine cultures for the same pathogen. In their study, a substantial minority did not have pyuria, and lower respiratory tract infection was often the erroneous admitting diagnosis.

Poor sensitivity for positive cultures does not infer poor sensitivity for UTI because, in the elderly, positive cultures do not necessarily confirm UTI. Positive cultures may also reflect asymptomatic bacteriuria and, given the high prevalence of bacteriuria in our asymptomatic group, it is possible that many or most of the positive cultures in our symptomatic cohort reflected asymptomatic bacteriuria, particularly given the lack of focal urinary-related symptoms. Of note, only 5 out of the 11 patients admitted with a positive culture had UTI as a primary or secondary discharge diagnosis, which supports the view that many positive cultures are 'false' positive. Neither a reagent test nor a positive culture result alone or in combination appears to be sufficient to diagnose a UTI in this population. Positive cultures must be interpreted in light of clinical presentation; hence, bacteriuria becomes 'urinary infection' when the patient has symptoms, particularly those related to the urinary tract. However, studies such as that by Barkham and colleagues suggest it may be difficult to define the symptoms that are compatible with UTI, and that vague systemic symptoms in the elderly are enough to warrant the suspicion of a UTI even in the presence of a negative dipstick urinalysis.

Our results showed that $61 \%$ of patients with positive reagent testing had negative cultures; therefore, basing treatment solely on a positive reagent test seems inappropriate in an elderly patient without focal urinary tract symptoms. These data, along with previous work, ${ }^{8}$ suggest that dependence on these low-specificity tests will lead to over treatment. Of interest, our physicians prescribed antibiotics for only $55.3 \%$ of symptomatic patients who had positive reagent tests, which suggests an awareness of the non-specific nature of reagent testing.

These results would support further study to identify reliable diagnostic criteria for UTI in elderly patients who have no focal symptoms, as well as to clarify when asymptomatic bacteriuria becomes a UTI. There are no definite criteria for treating asymptomatic bacteriuria in the elderly, and treatment of culture-positive patients who do not have a UTI is not without risk.

\section{Limitations}

As with any convenience cohort, there is a possibility of recruitment bias. In addition, we excluded long-term care patients and those with known urologic abnormalities, so our results cannot necessarily be generalized to those populations. With no predetermined criterion standard for the diagnosis of a UTI, final clinical diagnoses are suspect. Conclusions derived from these data should be confirmed in larger studies with more rigorous outcome assignment (if possible, based on a valid and reliable criterion standard). This was a 'real-world' study in which urine was captured in many ways. We cannot identify the proportion of specimens that were contaminated-particularly from patients with physical disabilities and those who were weak or confused.

\section{Conclusion}

In the elderly, reagent testing is an unreliable method of identifying patients with positive blood cultures. Moreover, positive urine culture rates are only slightly higher in patients with vague symptoms attributable to UTI than they are in (asymptomatic) patients treated for non-urologic problems, suggesting that many positive cultures in elderly patients with non-focal systemic symptoms are false-positive tests reflecting asymptomatic bacteriuria and not UTIs. Blood cultures, regarded by many as the criterion standard for UTI, do not have sufficient specificity to confirm the diagnosis of UTI in elderly patients with non-specific symptoms.

Competing interests: None declared.

\section{References}

1. Foxman B. Epidemiology of urinary tract infections: incidence, morbidity, and economic costs. Am J Med 2002;113(Suppl 1A): 5S-13S.

2. Orenstein R, Wong ES. Urinary tract infections in adults. Am Fam Physician 1999;59(5):1225-34,1237. 
3. Nickel JC, Pidutti R. A rational approach to urinary tract infections in older patients. Geriatrics 1992;47:49-50, 53-5.

4. Barkham TM, Martin FC, Eykyn SJ. Delay in the diagnosis of bacteraemic urinary tract infection in elderly patients. Age Ageing 1996;25:130-2.

5. Ackermann RJ, Monroe PW. Bacteremic urinary tract infection in older people. J Am Geriatr Soc 1996;44:927-33.

6. Deville WL, Yzermans JC, van Duijn NP, et al. The urine dipstick test useful to rule out infections. A meta-analysis of the accuracy. BMC Urol 2004;4:4.

7. Eidelman Y, Raveh D, Yinnon AM, et al. Reagent strip diagnosis of UTI in a high-risk population. Am J Emerg Med 2002;20:112-3.
8. Lammers RL, Gibson S, Kovacs D, et al. Comparison of test characteristics of urine dipstick and urinalysis at various test cutoff points. Ann Emerg Med 2001;38:505-12.

9. Lumbiganon $\mathrm{P}$, Chongsomchai C, Chumworathayee B, et al. Reagent strip testing is not sensitive for the screening of asymptomatic bacteriuria in pregnant women. J Med Assoc Thai 2002; 85:922-7.

10. Wagenlehner FM, Naber KG, Weidner W. Asymptomatic bacteriuria in elderly patients: significance and implications for treatment. Drugs Aging 2005;22:801-7.

Correspondence to: Dr. J. Ducharme, paindoc22000@yahoo.com

\section{Paladin Labs Inc.}

Twinject

$1 / 2$ page, 4 clr.,

Repeat of May 2006 